\title{
Minimally Invasive Evaluation and Treatment of Colorectal Liver Metastases
}

\author{
Anton L. Gueorguiev, ${ }^{1}$ Richard Mackey, ${ }^{2}$ Gopal C. Kowdley, ${ }^{1}$ \\ Jesus Esquivel,' and Steven C. Cunningham ${ }^{1}$ \\ ${ }^{1}$ Department of Surgery, Saint Agnes Hospital, 900 Caton Avenue, Mailbox no. 207, Baltimore, MD 21229, USA \\ ${ }^{2}$ Department of Surgery, Saint Joseph Hospital, Baltimore, MD 21231, USA
}

Correspondence should be addressed to Steven C. Cunningham, steven.cunningham@stagnes.org

Received 7 January 2011; Accepted 5 May 2011

Academic Editor: Abdullah Al Haddad

Copyright ( $) 2011$ Anton L. Gueorguiev et al. This is an open access article distributed under the Creative Commons Attribution License, which permits unrestricted use, distribution, and reproduction in any medium, provided the original work is properly cited.

\begin{abstract}
Minimally invasive techniques used in the evaluation and treatment of colorectal liver metastases (CRLMs) include ultrasonography (US), computed tomography, magnetic resonance imaging, percutaneous and operative ablation therapy, standard laparoscopic techniques, robotic techniques, and experimental techniques of natural orifice endoscopic surgery. Laparoscopic techniques range from simple staging laparoscopy with or without laparoscopic intraoperative US, through intermediate techniques including simple liver resections (LRs), to advanced techniques such as major hepatectomies. Hereins, we review minimally invasive evaluation and treatment of CRLM, focusing on a comparison of open LR (OLR) and minimally invasive LR (MILR). Although there are no randomized trials comparing OLR and MILR, nonrandomized data suggest that MILR compares favorably with OLR regarding morbidity, mortality, LOS, and cost, although significant selection bias exists. The future of MILR will likely include expanding criteria for resectability of CRLM and should include both a patient registry and a formalized process for surgeon training and credentialing.
\end{abstract}

\section{Introduction}

As the third commonest cancer in males and females and the second commonest cause of cancer death [1], colorectal cancer (CRC) is an important health problem in the world.

There are estimated to be 334000 new cases of CRC in Europe [2] and 142570 new cases in the United States [1], and $36 \%$ of these patients will succumb to their CRC [1]. Of all patients with CRC, approximately $65 \%$ develop distant metastasis, and the commonest location (40\%) is the liver [3]. The proportion of patients who presented with synchronous versus metachronous colorectal liver metastases (CRLMs) in France was equal in a recent epidemiologic study: the proportion of patients with synchronous CRLM and the 5-year rate of metachronous CRLM were both 14\% [4]. Unfortunately, only $25 \%$ of patients with CRLM are amenable to curative-intent treatment $[3,5-7]$.

Since the first report of a laparoscopic liver resection (LR) in 1992 (for CRLM) [8, 9], the field of minimally invasive liver resection (MILR) has seen tremendous advances, parallel- ing those of open liver resection (OLR), with increasing safety and efficacy. Although most early MILRs were for benign disease, the first report notwithstanding, an increasing volume of nonrandomized data suggests no oncologic disadvantage to performing MILR compared to OLR.

\section{Minimally Invasive Evaluation}

Transabdominal US is a widely available, inexpensive, and noninvasive technique of evaluating for CRLM but, compared with other modalities, has the lowest sensitivity and negative predictive value [10], excepting contrast-enhanced ultrasound, which by some studies is as sensitive as CT [11] but which is not available in the United States. Consequently, $\mathrm{CT}$ and MRI are among the most commonly employed modalities used to evaluate the liver for CRLM. A recent metaanalysis of diagnostic imaging of CRLM, evaluating 39 articles (3391 patients), found MRI to be the optimal first-line modality, with a per-patient sensitivity of $88 \%$ [12]. 
While early (1990s) studies showed staging laparoscopy (SL) to be superior to preoperative imaging in detecting unresectable or extrahepatic disease, thereby sparing as many as $34 \%$ of patients a laparotomy [13], when combined with intraoperative ultrasound (IOUS), even in an era of markedly improved axial imaging (2000s), SL was able to detect unresectable disease and potentially prevent unnecessary laparotomies in 10-25\% of patients with primary and secondary hepatic malignancies [14-16].

Increasing quality in preoperative axial imaging technology, however, has challenged the use of laparoscopic IOUS. In a prospective study of 194 patients undergoing LR for CRLM published in 2008, Tamandl et al. compared data from preoperative imaging using multidetector CT (MDCT) and MRI to intraoperative findings using IOUS and bimanual palpation and found that IOUS provided useful information regarding additional CRLM in only $2.6 \%$ of patients [17]. Other groups, however, have consistently found that $10 \%$ of additional small tumors that were missed by axial imaging may be detected $[18,19]$ and the preoperative treatment plan may change in nearly half of cases [15] when a complete evaluation is performed, including exposure of the entire surface of the liver and porta hepatis, an IOUS scan of all 8 liver segments, porta hepatis and the paraceliac nodal bed, and a thorough evaluation of the entire peritoneal cavity to detect extrahepatic metastases. Whether done laparoscopically or open, a complete US evaluation of the liver should include four steps: (1) an identification of intrahepatic vascular anatomy, (2) identification and characterization of known lesions, (3) a search for previously unrecognized lesions, and (4) the planning of a treatment strategy, which may include resection, ablation, or both. Intrahepatic tumors are evaluated for size, number, location, relationship to biliary and vascular structures, and echogenicity (most CRLMs are hypoechoic $(42 \%)$ or isoechoic $(43 \%)$, while a minority $(15 \%)$ are hyperechoic [18]). Echogenicity should be noted because it has been shown to correlate with long-term survival: in a prospective evaluation of 147 patients at Johns Hopkins Hospital, the 5-year survival for patients with hypo-, iso-, and hyperechoic CRLM was $14 \%, 37 \%$, and $46 \%$, respectively [20].

\section{Minimally Invasive Treatment Techniques}

3.1. Ablative Techniques. Standard ablative techniques include both chemical and thermal ablation and are increasingly used, both in isolation for patients with unresectable CRLM and in combination with LR. Chemical ablation with ethanol or acetic acid has been performed for CRLM but is less effective for CRLM than for hepatocellular carcinoma [21-23]. Thermal ablation is therefore the preferred treatment for CRLM not amenable to surgical resection. Thermal ablation includes radiofrequency ablation (RFA), microwave, laser, and cryoablation. In these techniques, focal heating or freezing of tumor cells causes local tumor destruction while preserving surrounding hepatic parenchyma. An emerging and still poorly studied technique is the nonthermal, nonchemical technique of electrical ablation using irreversible electroporation.

Although operative ablation of CRLM is often done in combination with both MILR and OLR, percutaneous ablation of CRLM is appropriate in cases in which no resection is planned and offers an attractive minimally invasive treatment option for such patients. However administered, RFA is relatively safe and less invasive than formal hepatic resection, but several notable complications may occur, including hepatic failure, hydrothorax, intraperitoneal bleeding, hepatic abscess, bile duct leaks, and tumor seeding [24$28]$. The reported procedure-related morbidity ranges from $2 \%$ to $12 \%$ and the mortality rate from $0 \%$ to $4.3 \%$ [24, 26-29]. Many of these reports, however, include a variety of approaches, including percutaneous, laparoscopic, and open, and include more cases of HCC than CRLM [24, 2729]. Given the frequent association of HCC with cirrhosis, complications such as bleeding, liver failure, and death may be more common following ablation of HCC than CRLM $[24,27]$. In a recent report of 100 patients undergoing RFA for CRLM, there was no procedure-related morality and the major complication rate was $8 \%$ [30]. Another study of 100 patients undergoing RFA (146 treatments) for CRLM revealed a major complication rate of $4.8 \%$, including 1 death from liver failure [31]. Gillams and Lees similarly found a major complication rate of $4.0 \%$ in a series of 167 patients undergoing RFA for CRLM [32].

Microwave ablation (MWA) is an emerging technology that can also be performed open, percutaneously, or laparoscopically. Like with RFA, however, no randomized trials support its use over other techniques. The primary theoretical advantages of MWA are the ability to ablate larger lesions and to do so faster. These advantages likely derive from the fact that MWA, unlike RFA, does not rely on electric current and so is not impeded by tissue desiccation and charring, both of which decrease electrical conductivity. In addition, there is no so-called "heat sink" effect, or heat loss from adjacent blood vessels, which in the case of RFA decreases the effectiveness and increases the time required for ablation. Most reported experiences have demonstrated safe and effective MWA, with complications and local recurrence rates comparable to RFA [33-35]. Theoretical disadvantages include the inadvertent injury to adjacent structures and the risk of such collateral damage makes tumor location important in the decision of which modality (e.g., RFA versus MWA) and route (e.g., open versus laparoscopic) to choose. Ablation of dome lesions or left lateral segment lesions, for instance, could expose the diaphragm and heart to thermal injury and serious morbidity, and such lesion may be better treated with an open or laparoscopic as opposed to percutaneous technique.

Cryoablation can similarly be performed via percutaneous or open approaches. It offers many of the same benefits of RFA and MWA, such as preservation of liver parenchyma, but at a potentially increased cost, given that the complication rates may be higher compared with RFA: morbidity $10-40 \%$ and mortality $0-5 \%$ [36]. Complications include hepatic/iceball fracture (19\%), hemorrhage (3.7\%), 
coagulopathy (3.8\%), biliary fistula (2.9\%), and organ failure [36]. Furthermore, animal models have demonstrated that there is a more severe systemic response following cryotherapy than following RFA [37].

Irreversible electroporation (IRE) is an emerging, nonthermal, nonchemical technique that uses electrical current to destroy cells. Its reversible counterpart, reversible electroporation, is a common laboratory technique that has been employed for decades to transiently render cells widely permeable to allow entry of large molecules such as drugs and genes by applying an electrical field to cells that are otherwise not permeable to the molecules of interest [38]. IRE, previously viewed as an undesireable upper limit of reversible electroporation because it rendered the cells permanently permeable and therefore nonviable, is now used clinically as a form of nonthermal ablation. While supported by animal models [39-41] and available commercially for use in patients, IRE has not been well studied in patients. It does have the theoretical advantages, however, of being very fast (micro- to milliseconds), preserving connective tissue architecture thereby allowing ablation close to vital structures in the liver hilum for example, and unlike thermal techniques it is not likely affected by blood flow [38]. As with many new techniques, all cases of IRE performed should be registered to document the role and safety of IRE, as well as to identify important questions for study in clinical trials, and indeed such a registry is underway at the University of Louisville [42].

\subsection{Ablation and Resection.}

(1) Surgical resection is the standard of care for CRLM, but RFA has produced comparable outcomes for limited disease, with some important caveats. Although RFA has demonstrated 5-year survival rates as high as $30 \%$ in some studies $[31,32]$ and numerous other studies have attempted to compare resection and ablation [43-47], recent analyses using propensity score methodology $[48,49]$ have shown that comparison of survival rates following RFA and resection is not reliable, due to major differences in clinicopathologic characteristics, RFA technologies and expertise, and analysis of margin status (namely, lack of pathologic analysis after RFA since no specimen is available). Until randomized controlled trials comparing RFA and surgical resection are available, the question of their comparability will likely remain unanswered [50]. In a recent systematic review performed by the American Society of Clinical Oncology in 2009 regarding RFA for CRLM [51], over 400 published articles were reviewed, 46 identified as having over 10 patients with adequate followup and perioperative data to analyze. There was a wide variability in the reported 5-year survival (14-55\%) and local tumor recurrence $(3.6-60 \%)[51]$.

While comparisons to resection may be unreliable and largely unrevealing, comparisons within RFA series have been more fruitful. For instance, it has become clear that increasing CRLM size-especially size $>3 \mathrm{~cm}$-is directly proportional to shorter survival and higher rates of recurrence [52-54]. While some studies have found this to be true regardless of the approach (open, laparoscopic, or percutaneous) [53], other studies have found worse local tumor recurrence and disease-free survival in percutaneously treated patients compared with open cases [55]. Prognostic factors that contribute to overall outcome include node status of the primary CRC resection, synchronous versus metachronous disease, number and size of lesions, margin status of resected hepatic lesions, CEA levels, the presence of extrahepatic disease, satellite lesions and systemic treatment [51]. RFA is an operator-dependent procedure, whether open, laparoscopic, or percutaneous, and requires careful technique and patient selection to achieve optimal outcomes.

\subsection{Laparoscopic LR, Hand-Assisted Laparoscopic Surgery} (HALS), and Hybrid Approaches. Although initial laparoscopic liver surgery was typically limited to wedge resections of benign lesions that were easily accessible $[8,9,56]$, more advanced liver resections are now performed laparoscopically, including totally laparoscopic right, left, and central hepatectomies, extended right and left hepatectomies, and posterosuperior resections [57-63].

Many surgeons wishing to perform MILR begin a stepwise process of beginning with easy minor resections (Figure 1), later using a hand port [64-67] or hybrid technique [68] for complex resections before finally attempting totally laparoscopic major resections. However, even when the dissection and transection of the liver is totally laparoscopic in cases of extended hepatectomies, the specimen is large and requires an incision for removal $[58,59]$. This incision is often as long as that required for a hand port, which is one reason that many have advocated for maintaining - and in some cases returning to- $a$ hand-assisted as opposed to a totally laparoscopic approach $[66,67]$. The main advantages of HALS are tactile feedback, including ability to palpate the liver, tumor, and nodes, facile liver mobilization and retraction, quick and easy hemostasis with digital compression in cases of unexpected hemorrhage, and the multiple additional uses of the hand-port incision, including placement of additional instruments and removal of the specimen.

The hybrid technique, combining the relatively basic laparoscopic skills of liver mobilization with the more advanced but open dissection of the liver hilum and transection of the liver parenchyma through a minilaparotomy, the small size of which is made possible by the laparoscopic mobilization [68], is another effort to shorten the learning curve (see below) associated with MILR, thereby increasing the numbers of patients who may benefit from MILR. The hybrid approach, like the HALS approach, is meant to combine the advantages of laparoscopic surgery (decreased postoperative pain and improved cosmesis, largely due to the avoidance of a subcostal incision) with the safety, ease, and accessibility provided in open procedures.

3.4. Robotic Liver Resection. Robotic surgery overcomes certain limitations encountered with the laparoscopic technique, such as 2-dimensional images and linear instruments, 


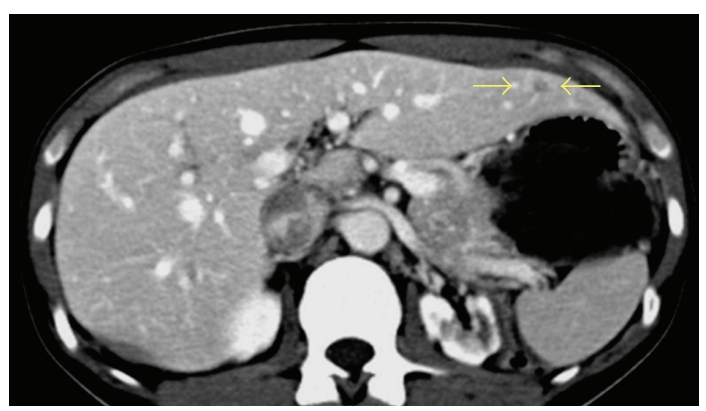

(a)

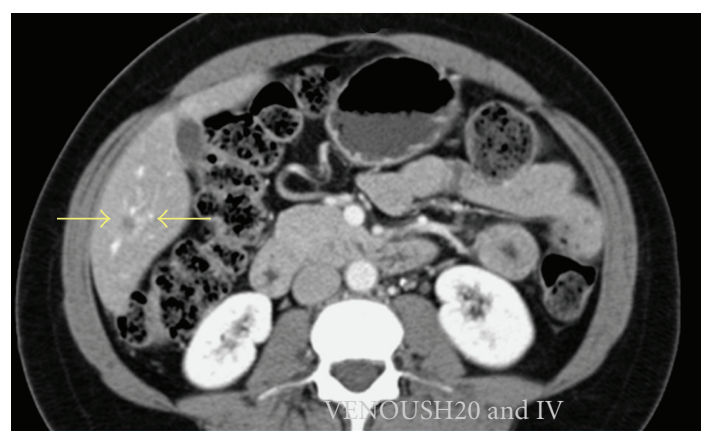

(b)

FIgURE 1: CRLMs accessible for straightforward MILR. (a) A hypodense CRLM in segments 2/3; (b) A hypodense CRLM in segment 6 .

and offers clear advantages such as 3-dimensional imaging, tremor filtration, higher magnification, and articulating instruments with seven degrees of freedom. These advantages allow improved visualization and improved surgeon dexterity for fine movements, especially intracorporeal suturing.

Disadvantages inherent in the complex robotic technology include significant expense of the acquisition and maintenance of a robotic system, longer operating times, a significant learning curve to becoming proficient with the setup and utilization of the instruments, a loss of tactile feedback, and the requirement of a skilled assistant, as both the assistant and console surgeon perform integral parts of the hepatic transection $[69,70]$.

The worldwide experience with robotic LR is somewhat limited with approximately 100 reported cases, but the approach appears to be safe in experienced hands [71-74]. The largest series from Giulianotti et al. [71] reported 70 patients, 66 of whom underwent successful robotic resection and 16 of whom had colorectal metastases (4 minor resections and 12 major). The average surgical margin for colorectal metastases was $25 \mathrm{~mm}$ and the overall morbidity was $21 \%$ with a mortality of $0 \%$ and a median length of stay (LOS) of 7 days [71]. Two smaller series of robotic hepatectomies for CRLM and other diagnoses Berber et al. [73] and Ji et al. [74] appear to have similar outcomes with 9 patients and 13 patients, respectively. The margins were not compromised in either group, with morbidity ranging from 7.8 to $11 \%$, with no mortality $[73,74]$. Even very complex cases, such as singlestage, combined liver and colon resection for synchronous
CRLM, have been performed with robotassisted laparoscopy [75].

3.5. Laparoscopic Placement of Hepatic Artery Infusion (HAI) Catheter. Given that a number of studies suggest that regional (as opposed to systemic) chemotherapy may improve the response CRLM and possibly improve survival in patients with resectable and unresectable CRLM [76-80], the principle rational for HAI catheter is that CRLMs derive $80 \%$ to $100 \%$ of their blood supply from the hepatic artery, as opposed to the portal vein [81]. This allows for a high concentration of chemotherapeutic agents to be delivered directly into the tumors, with maximal effect on the metastatic lesion, minimal parenchymal and systemic toxicity, and minimal loss of activity due to the first-pass hepatic extraction [82]. The laparoscopic approach provides a minimally invasive way to obtain such an access to the hepatic artery by avoiding the morbidity and mortality associated with standard laparotomy procedures. Multiple studies have shown that laparoscopic HAC placement is a feasible and safe procedure [83-85].

3.6. Transarterial Embolization, Chemoembolization, and Radioembolization. Hepatic artery infusion is only one of several ways to deliver therapies transarterially to the liver, thereby minimizing systemic toxicities. Other transarterial therapies include transarterial embolization (TAE), transarterial chemoembolization (TACE), and intra-arterial radiotherapy (IART), among others, all of which share with HAI the advantages associated with delivery of therapy via the hepatic arterial system. There is not an overabundance of highquality data supporting either TAE or TACE over the other, and, when compared, both have produced median survival results of $8-12$ months $[86,87]$. Nevertheless, since TACE provides two therapies in one-both an ischemic and a toxic insult to the CRLM-it is generally preferred. Albert et al. recently evaluated 121 patients undergoing 245 TACE treatments and found a 27-month overall median survival using cisplatin, doxorubicin, mitomycin $\mathrm{C}$, ethiodized oil, and polyvinyl alcohol particles [88]. Neither TACE nor TAE is as well studied as the treatment of CRLM compared with hepatocellular carcinoma, and more data are needed to define this role.

Similarly, IART is the embolization of a radiation-emitter into the hepatic arteries feeding the CRLM. The only FDAapproved agent is yttrium-90, a radioisotope that emits highenergy beta-particles, which was recently compared in a small phase-I study with FOLFOX for unresectable CRLM [89]. A radiographic partial response was observed in $90 \%$ $(18 / 20)$ of patients and stable disease in $10 \%(2 / 20)$, with a progression-free survival of 9.3 months [89]. As with TAE and TACE, a lack of high-quality data exists, as evidenced by a recent Cochrane review [90] that included only one randomized study: van Hazel et al. [91] compared IART plus systemic chemotherapy and systemic chemotherapy alone and found significantly longer progression-free survival following IART. As with TACE and TAE, more data are needed to improve decision-making in patients with advanced CRLM. 


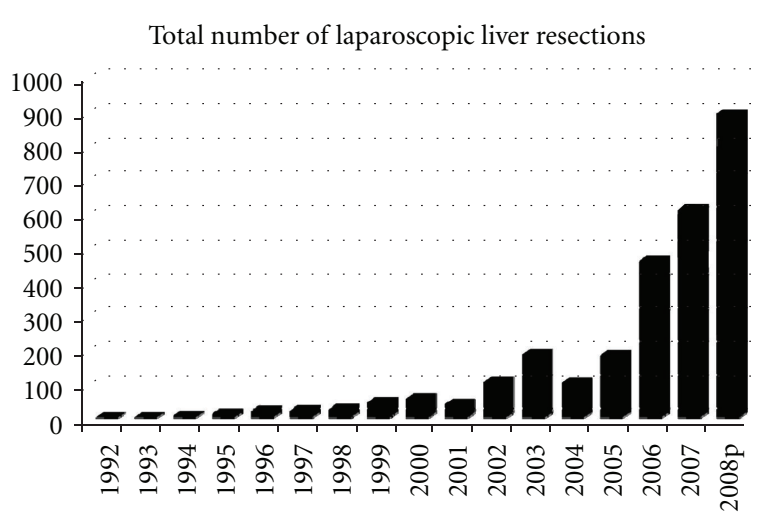

(a)

Benign versus malignant lesions

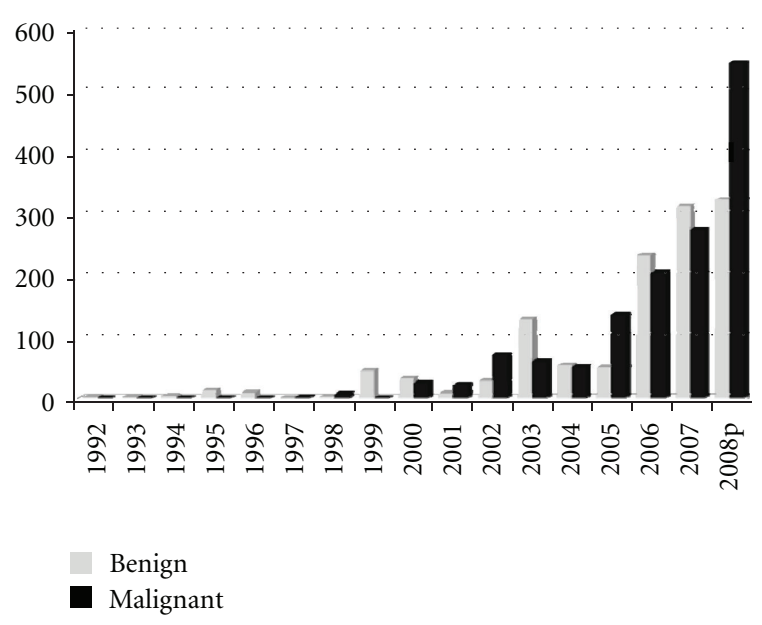

(b)

Figure 2: Increase in reported MILRs over time (2002-2008 (partial)). Reproduced from Nguyen et al. Annals of Surgery 2009; $250: 831$ [92].

\section{Comparison of OLR and MILR for CRLM}

4.1. Oncologic Outcomes. The treatment of choice for CRLM is surgical resection. As minimally invasive techniques, surgeon familiarity with those techniques, and minimally invasive instruments-particularly coagulation and stapling devices - have improved, the number of patients undergoing MILR has increased exponentially in the recent years (Figure 2 [92]). Although early series reported resections that were typically minor and performed for benign disease [93], increased experience has lead to more aggressive MILR including malignant lesions and major hepatic resections. Early criticism of MILR was aimed at feared inability to maintain oncologic integrity. Indeed, similar concerns were weighed against laparoscopic colon resection until randomized trials supported equivalent safety, negative-margins status, and disease-free survival [94, 95]. A large and growing global experience (but no randomized controlled trials) suggests that laparoscopic resection is safe and effective for the management of liver lesions while maintaining oncologic integrity $[64,65,92]$.
In the absence of randomized controlled trials comparing MILR with OLR, several observational studies have compared these modalities, including cohort studies, case-controlled studies, and intention-to-treat studies [96-103]; although they show similar rates of complications and survival, many of these contain mixed patient populations including benign and various malignant histologies. Nguyen and colleagues reviewed all laparoscopic resections performed exclusively for CRLM from 2000 to 2008 . They identified 109 cases, $97 \%$ of which were completed laparoscopically with a $94 \%$ negative-margin rate [104]. Forty-five percent of patients underwent a major ( $\geq 3$ segments) hepatectomy, with no mortalities and a $12 \%$ complication rate; actuarial survival at 1,3 , and 5 years was $88 \%, 69 \%$, and $50 \%$, respectively [104], although no comparison to an open cohort was made. Castaing et al. compared matched cases of laparoscopic and open hepatectomy performed for CRLM and reported comparable 5-year survival rates of $64 \%$ and $56 \%$ for laparoscopic and open LR, respectively [105], thus supporting comparable oncologic outcomes. While the majority of the laparoscopic resections reported in the literature are minor (<3 segments), Dagher and colleagues studied a series of 210 major hepatectomies from 5 institutions, with 114 for malignant disease [106], reporting a mortality of $1 \%$ (nonliver-related) and an overall morbidity of $22 \%$ (8.1\% liverrelated: $6.2 \%$ bile leak, $1.4 \%$ ascites, and $0.5 \%$ hemorrhage). Positive margins were identified in only 3 patients $(2.6 \%)$ [106], which compares favorably to the rate of margin positivity in OLR for CRLM which has had a wide variance from 5 to $24 \%$ [107-109].

4.2. Caveats. Although margin status and oncologic outcomes appear favorable these results should be interpreted with caution, since selection bias is inherent in nonrandomized studies and patients deemed laparoscopic candidates may represent a different and more favorable group. In the Castaing series, for instance, the operative details are variable, with vascular clamping occurring in $92 \%$ of the open versus $17 \%$ in the laparoscopic group [105]. An interesting study performed by Welsh et al. reviewed all patients who underwent OLR for CRLM and divided them into 2 groups, one suitable for MILR and another deemed best candidates for OLR. Even though all resections were done open, those identified as MILR candidates had a lower positive-margin rate $(4.5 \%$ versus $15 \%)$ and better 5 -year survival $(44 \%$ versus $37 \%$ ) [110].

Randomized data comparing MILR and OLR are, unfortunately, unlikely to be obtained because of difficulty in defining end points (safety versus cost versus efficacy), none of which were deemed good end points for such a trial in the recent international consensus Louisville Statement [64], because of heterogeneity of the patient population and because of the length of time needed to accumulate enough patients. The Louisville Statement did support a prospective registry with preoperative enrollment, the creation of which would help track the dissemination of procedures aimed at improving patient safety [64]. Although initial nonrandomized data suggest that MILR is likely a safe, oncologically 
sound means of managing CRLM, ongoing critical review, multidisciplinary teams and participation in prospective data collection or trials will continue to define optimal approach to CRLM.

4.3. Cost and LOS. Examination of cost has been reported by several groups in retrospective series. In a subgroup analysis from the University of Louisville, Buell et al. retrospectively reviewed and compared 29 laparoscopic and 34 open resections, finding significant actual cost savings for a laparoscopic approach to major resections $(\$ 21,131$ versus $\$ 36,821$; $P<0.01)$ before, but not after, adjustment for changes in Diagnosis-Related Group coding (\$25,457 versus \$23,691; $P<0.2$ ) [111]. In a retrospective comparison of open versus laparoscopic left lateral segmentectomy, Vanounou et al. at the University of Pittsburgh used deviation-based cost modeling to analyze open and laparoscopic liver resections (for both benign and malignant diseases) and found that the overall LOS was 2 days shorter for the laparoscopic cases, which was associated with a per-patient cost reduction of $\$ 2939$ compared to open cases [112]; when only malignant cases were considered, however, that cost reduction was attenuated at $\$ 1527$ per patient.

Although both the Louisville and the Pittsburgh studies showed significantly shorter LOS for MILR versus OLR, other data, derived from comparing standard recovery pathway versus a fast-track recovery pathway following OLR, have found a similar reduction in LOS (2 days) following fasttrack recovery [113]. Indeed, it has been argued [110, 114, 115 ] that LOS is determined more by extent of resection than by operative approach and may be as little as 2-4 days with either laparoscopic or open approach.

\section{Future Directions and Controversies}

5.1. Training and Credentialing. Broad surgical experience, corroborated by many studies [116-118], demonstrates the learning curve for MILR. Simillis et al., for instance, showed that only in studies published after 2003 and in studies including $\geq 20$ laparoscopic procedures did the operative blood loss, LOS, and complications decrease for laparoscopic liver surgery when compared to open LR [117]. As the number of MILR cases performed increases worldwide at a tremendous rate (Figure 2 [92]) and as the MILR community increasingly recognizes the infeasibility of performing randomized trials of MILR [64], there have been many calls for an international registry $[64,92]$ of MILR to maintain a record for monitoring outcomes of efficacy and patient safety, as has already been achieved for natural orifice transluminal endoscopic surgery [119], an experimental modality much more widely used for cholecystectomy ( $85 \%$ of all NOTES procedures) [119] than for MILR [120, 121].

Training and credentialing of MILR are currently performed at the local level and left to individual institutions. At a minimum a strong combined expertise in major laparoscopic surgery and advanced hepatobiliary techniques, including knowledge and skill in the use of intraoperative ultrasound, is required of a surgeon who wishes to begin the learning curve for MILR $[64,117]$. Currently, however, there are no clear, widely accepted criteria that define this required expertise [64]. A certification process for MILR has also yet to be defined and the American Hepato-PancreatoBiliary Association does not currently require a specific number of MILR cases for the training of hepatobiliary surgeons [122]. Many surgeons, however, recognize the need for a systematic progression from basic to advanced laparoscopic and hepatobiliary skills then to combined advanced laparoscopic and hepatobiliary skills, and some have published their experience with starting an MILR program from scratch [123].

\subsection{Learning Curve Effect.}

(1) The learning-curve effect has not been studied extensively in laparoscopic liver surgery. Numerous singleinstitution series have shown an improvement in outcomes when the latter experience is compared to the early experience $[124,125]$. The first detailed analysis evaluating the learning curve effect in MILR was published by Vigano et al. in 2009, revealing significantly improved operative time, conversion rate, blood loss, morbidity, and hospital stay progressively over time as experience and volume increased, despite an increase in operative complexity over time [126]. The shape of the learning curve was, not surprisingly, similar to those reported regarding laparoscopic colectomy [127]. These results suggest that MILR is reproducible in selected high-volume centers, by surgeons with advanced laparoscopic and hepatobiliary training.

\subsection{Combined Liver and Lung Metastases.}

(1) Although the liver is the most common site of colorectal metastasis [3], another $3.5 \%$ of patients with colon-and $11.5 \%$ of patients with rectal-cancer will develop lung metastasis [128], most of whom have both liver and lung diseases. Although early (prior to 2001) studies of curative-intent metastasectomy in patients with combined hepatic and pulmonary colorectal metastases found widely variable 5-year survival rates, ranging from $11 \%$ to $44 \%$ [129$132]$, more recent retrospective studies have produced improved 5-year survival rates as high as $64 \%$ [133-137] in patients with colorectal pulmonary metastases. Although fewer data are available regarding minimally invasive treatment of pulmonaryas compared to hepatic - colorectal metastases, large recent series have shown that pulmonary metastasectomies may be performed with minimally invasive video-assisted thoracic surgery [137]. Another, even less invasive option is RFA of pulmonary metastases. Yamakado et al. recently studied a series of 78 patients with 198 colorectal lung metastases treated with RFA, reporting a 5 -year and median survival of $35 \%$ and 38 months, respectively [138]. 


\subsection{Combined Liver and Peritoneal Metastases.}

(1) Large series of patients with CRC have revealed that $4 \%$ to $19 \%$ of patients have colorectal carcinomatosis at the time of the CRC resection or in follow up, although as many as $80 \%$ of patients who die of CRC have developed carcinomatosis by the time of their death $[139,140]$. In a review of nearly 3000 cases of CRC in Singapore, 349 (13\%) had carcinomatosis, $61 \%$ (214) of whom had disease that was synchronous-and 39\% (135) metachronous-with their initial presentation of CRC [139]. The proportions of CRLM patients with no carcinomatosis, with metachronous carcinomatosis, and with synchronous carcinomatosis were $10 \%, 33 \%$, and $42 \%$, respectively, respectively [139]. An increasing body of data [141], including randomized controlled data [142], suggests that complete surgical eradication of metastatic peritoneal disease with cytoreduction and hyperthermic intraperitoneal chemotherapy (HIPEC) is beneficial to selected patients with colon cancer with carcinomatosis, with 5-year survival rates $>50 \%$ recently reported [143].

Although the presence of CRLM is often considered a contraindication to cytoreduction and HIPEC, and similarly the presence of carcinomatosis a contraindication to LR, several recent studies [144-147] have evaluated the combination of cytoreduction, HIPEC, and liver resection as an aggressive emerging option for highly selected CRC patients with both CRLM and peritoneal carcinomatosis. Elias et al. [147] evaluated a series of 24 such patients with a mean Peritoneal Cancer Index (PCI) [148] of 8.6 (range: 2-25), half of whom underwent a major hepatectomy, and reported one postoperative death, a morbidity of $58 \%$, and an overall 2-year survival of $61 \%$. Patients with $\geq 3$ CRLM had significantly worse survival compared with patientS who had $<3$ CRLM [147]. More recently Chua et al. [144] evaluated a series of 16 patients with both CRLM and carcinomatosis treated by combined cytoreduction, HIPEC, and liver resection and reported a 2-year survival of $65 \%$; neither survival nor perioperative factors such as morbidity and LOS were different compared with patients who had isolated carcinomatosis without CRLM, although those with both CRLM and carcinomatosis had significantly lower PCI compared with patients with isolated carcinomatosis [144]. Most patients with CRLM and peritoneal carcinomatosis are not, however, currently candidates for aggressive surgical resection of their CRLM and these emerging data should be interpreted with caution.

Minimally invasive techniques have been used to perform cytoreduction to palliate metastatic disease to the ovaries [149], to completely remove primary ovarian carcinomas with limited peritoneal dissemination [150], and to do staged laparoscopic HIPEC following open cytoreduction [151]. The results of an ongoing protocol on laparoscopic cytoreduction and HIPEC in patients with limited peritoneal dissemination appear promising and compare favorably to those patients having an open cytoreductive procedure [152], suggesting that combining MILR and minimally invasive cytoreduction and HIPEC is on the horizon.

\section{Summary}

The number of cases of MILR performed in the world has increased exponentially in recent years, and many centers are now performing major, complex resections. In the absence of randomized trials comparing OLR and MILR, which is not likely obtainable, nonrandomized data suggest that MILR produces similar or improved morbidity, mortality, LOS, and cost compared with OLR, although significant selection bias exists. Because randomized data will be difficult or impossible to obtain, patient registries should be used to track safety and efficacy outcomes. Training of surgeons similarly should become more formalized, including an independent process for surgeon credentialing.

\section{References}

[1] A. Jemal, R. Siegel, J. Xu, and E. Ward, "Cancer statistics, 2010," CA Cancer Journal for Clinicians, vol. 60, no. 5, pp. 277-300, 2010.

[2] F. Bray, R. Sankila, J. Ferlay, and D. M. Parkin, "Estimates of cancer incidence and mortality in Europe in 1995," European Journal of Cancer, vol. 38, no. 1, pp. 99-166, 2002.

[3] C. Pestana, R. J. Reitemeier, C. G. Moertel, E. S. Judd, and M. B. Dockerty, "The natural history of carcinoma of the colon and rectum," The American Journal of Surgery, vol. 108, no. 6, pp. 826-829, 1964.

[4] S. Manfredi, C. Lepage, C. Hatem, O. Coatmeur, J. Faivre, and A. M. Bouvier, "Epidemiology and management of liver metastases from colorectal cancer," Annals of Surgery, vol. 244, no. 2, pp. 254-259, 2006.

[5] G. Steele Jr. and T. S. Ravikumar, "Resection of hepatic metastases from colorectal cancer: biologic perspectives," Annals of Surgery, vol. 210, no. 2, pp. 127-138, 1989.

[6] M. A. Choti, "Controversies in the management of hepatic colorectal metastases," Annals of Surgical Oncology, vol. 16, no. 9, pp. 2383-2384, 2009.

[7] R. Adam, V. Delvart, G. Pascal et al., "Rescue surgery for unresectable colorectal liver metastases downstaged by chemotherapy: a model to predict long-term survival," Annals of Surgery, vol. 240, no. 4, pp. 644-658, 2004.

[8] M. Gagner, "Pioneers in laparoscopic solid organ surgery," Surgical Endoscopy, vol. 17, no. 11, pp. 1853-1855, 2003.

[9] M. Gagner, M. Rheault, and J. Dubuc, "Laparoscopic partial hepatectomy for liver tumor," Surgical Endoscopy, vol. 6, no. 99, 1993.

[10] R. Carter, D. Hemingway, T. G. Cooke et al., "A prospective study of six methods for detection of hepatic colorectal metastases," Annals of the Royal College of Surgeons of England, vol. 78, no. 1, pp. 27-30, 1996.

[11] S. R. Rafaelsen and A. Jakobsen, "Contrast-enhanced ultrasound vs multidetector-computed tomography for detecting liver metastases in colorectal cancer: a prospective, blinded, patient-by-patient analysis," Colorectal Disease, vol. 13, no. 4, pp. 420-425, 2011.

[12] M. C. Niekel, S. Bipat, and J. Stoker, "Diagnostic imaging of colorectal liver metastases with CT, MR imaging, FDG PET, and/or FDG PET/CT: a meta-analysis of prospective studies 
including patients who have not previously undergone treatment," Radiology, vol. 257, no. 3, pp. 674-684, 2010.

[13] T. J. Babineau, W. D. Lewis, R. L. Jenkins, R. Bleday, G. D. Steele, and R. A. Forse, "Role of staging laparoscopy in the treatment of hepatic malignancy," American Journal of Surgery, vol. 167, no. 1, pp. 151-155, 1994.

[14] W. R. Jarnagin, J. Bodniewicz, E. Dougherty, K. Conlon, L. H. Blumgart, and Y. Fong, "A prospective analysis of staging laparoscopy in patients with primary and secondary hepatobiliary malignancies," Journal of Gastrointestinal Surgery, vol. 4, no. 1, pp. 34-43, 2000.

[15] K. Thaler, S. Kanneganti, Y. Khajanchee et al., "The evolving role of staging laparoscopy in the treatment of colorectal hepatic metastasis," Archives of Surgery, vol. 140, no. 8, pp. 727-734, 2005.

[16] S. R. Grobmyer, Y. Fong, M. D’Angelica, R. P. DeMatteo, L. H. Blumgart, and W. R. Jarnagin, "Diagnostic laparoscopy prior to planned hepatic resection for colorectal metastases," Archives of Surgery, vol. 139, no. 12, pp. 1326-1330, 2004.

[17] D. Tamandl, B. Herberger, B. Gruenberger et al., "Adequate preoperative staging rarely leads to a change of intraoperative strategy in patients undergoing surgery for colorectal cancer liver metastases," Surgery, vol. 143, no. 5, pp. 648-657, 2008.

[18] M. G. van Vledder, T. M. Pawlik, S. Munireddy, U. Hamper, M. C. De Jong, and M. A. Choti, "Factors determining the sensitivity of intraoperative ultrasonography in detecting colorectal liver metastases in the modern era," Annals of Surgical Oncology, vol. 17, no. 10, pp. 2756-2763, 2010.

[19] A. Foroutani, A. M. Garland, E. Berber et al., "Laparoscopic ultrasound vs triphasic computed tomography for detecting liver tumors," Archives of Surgery, vol. 135, no. 8, pp. 933-938, 2000.

[20] M. L. DeOliveira, T. M. Pawlik, A. L. Gleisner, L. Assumpcaom, G. J. Lopes-Filho, and M. A. Choti, "Echogenic appearance of colorectal liver metastases on intraoperative ultrasonography is associated with survival after hepatic resection," Journal of Gastrointestinal Surgery, vol. 11, no. 8, pp. 970-976, 2007.

[21] D. Becker, J. M. Hansler, D. Strobel, and E. G. Hahn, "Percutaneous ethanol injection and radio-frequency ablation for the treatment of nonresectable colorectal liver metastasestechniques and results," Langenbeck's Archives of Surgery, vol. 384, no. 4, pp. 339-343, 1999.

[22] B. Yamane and S. Weber, "Liver-directed treatment modalities for primary and secondary hepatic tumors," Surgical Clinics of North America, vol. 89, no. 1, pp. 97-113, 2009.

[23] M. Giovannini and J. F. Seitz, "Ultrasound-guided percutaneous alcohol injection of small liver metastases: results in 40 patients," Cancer, vol. 73, no. 2, pp. 294-297, 1994.

[24] W. T. Kong, W. W. Zhang, Y. D. Qiu et al., "Major complications after radiofrequency ablation for liver tumors: analysis of 255 patients," World Journal of Gastroenterology, vol. 15, no. 21, pp. 2651-2656, 2009.

[25] E. Buscarini, A. Savoia, G. Brambilla et al., "Radiofrequency thermal ablation of liver tumors," European Radiology, vol. 15, no. 5, pp. 884-894, 2005.

[26] T. de Baere, O. Risse, V. Kuoch et al., "Adverse events during radiofrequency treatment of 582 hepatic tumors," American Journal of Roentgenology, vol. 181, no. 3, pp. 695-700, 2003.

[27] T. Livraghi, L. Solbiati, M. F. Meloni, G. S. Gazelle, E. F. Halpern, and S. N. Goldberg, "Treatment of focal liver tumors with percutaneous radio-frequency ablation: complications encountered in a multicenter study," Radiology, vol. 226, no. 2, pp. 441-451, 2003.
[28] H. Rhim, K. H. Yoon, J. M. Lee et al., "Major complications after radio-frequency thermal ablation of hepatic tumors: spectrum of imaging findings," Radiographics, vol. 23, no. 1, pp. 123-136, 2003.

[29] E. Buscarini and L. Buscarini, "Radiofrequency thermal ablation with expandable needle of focal liver malignancies: complication report," European Radiology, vol. 14, no. 1, pp. 31-37, 2004.

[30] A. A. Van Tilborg, M. R. Meijerink, C. Sietses et al., "Longterm results of radiofrequency ablation for unresectable colorectal liver metastases: a potentially curative intervention," The British Journal of Radiology, vol. 84, no. 1002, pp. 556565, 2011.

[31] J. Machi, A. J. Oishi, K. Sumida et al., "Long-term outcome of radiofrequency ablation for unresectable liver metastases from colorectal cancer: evaluation of prognostic factors and effectiveness in first- and second-line management," Cancer Journal, vol. 12, no. 4, pp. 318-326, 2006.

[32] A. R. Gillams and W. R. Lees, "Radio-frequency ablation of colorectal liver metastases in 167 patients," European Radiology, vol. 14, no. 12, pp. 2261-2267, 2004.

[33] C. Boutros, P. Somasundar, S. Garrean, A. Saied, and N. J. Espat, "Microwave coagulation therapy for hepatic tumors: review of the literature and critical analysis," Surgical Oncology, vol. 19, no. 1, pp. e22-e32, 2010.

[34] R. C. G. Martin, C. R. Scoggins, and K. M. McMasters, "Safety and efficacy of microwave ablation of hepatic tumors: a prospective review of a 5-year experience," Annals of Surgical Oncology, vol. 17, no. 1, pp. 171-178, 2010.

[35] D. A. Iannitti, R. C. G. Martin, C. J. Simon et al., "Hepatic tumor ablation with clustered microwave antennae: the US phase II trial," HPB - Journal of the International Hepato Pancreato Biliary Association, vol. 9, no. 2, pp. 120-124, 2007.

[36] J. K. Seifert and T. Junginger, "Cryotherapy for liver tumors: current status, perspectives, clinical results, and review of literature," Technology in Cancer Research and Treatment, vol. 3, no. 2, pp. 151-163, 2004.

[37] K. K. Ng, C. M. Lam, R. T. Poon et al., "Comparison of systemic responses of radiofrequency ablation, cryotherapy, and surgical resection in a porcine liver model," Annals of Surgical Oncology, vol. 11, no. 7, pp. 650-657, 2004.

[38] B. Rubinsky, "Irreversible electroporation in medicine," Technology in Cancer Research and Treatment, vol. 6, no. 4, pp. 255-260, 2007.

[39] K. P. Charpentier, F. Wolf, L. Noble, B. Winn, M. Resnick, and D. E. Dupuy, "Irreversible electroporation of the liver and liver hilum in swine," $H P B$ - Journal of the International Hepato Pancreato Biliary Association, vol. 13, no. 3, pp. 168173, 2011.

[40] E. W. Lee, C. Chen, V. E. Prieto, S. M. Dry, C. T. Loh, and S. T. Kee, "Advanced hepatic ablation technique for creating complete cell death: irreversible electroporation," Radiology, vol. 255, no. 2, pp. 426-433, 2010.

[41] R. E. Brown, M. R. Bower, X. Li et al., "Nonthermal liver ablation by irreversible electroporation: results in a preclinical porcine model," in Proceedings of the 9th World Congress of the International Hepato-Pancreato-Biliary Association, Buenos Aires, Argentina, May 2010.

[42] Registry, "Ablation Registry for Unresectable Soft Tissue Tumors," http://www.ablationregistry.com/.

[43] T. A. Aloia, J. N. Vauthey, E. M. Loyer et al., "Solitary colorectal liver metastasis: resection determines outcome," Archives of Surgery, vol. 141, no. 5, pp. 460-467, 2006. 
[44] W. S. Lee, S. H. Yun, H. K. Chun et al., "Clinical outcomes of hepatic resection and radiofrequency ablation in patients with solitary colorectal liver metastasis," Journal of Clinical Gastroenterology, vol. 42, no. 8, pp. 945-949, 2008.

[45] E. K. Abdalla, J. N. Vauthey, L. M. Ellis et al., "Recurrence and outcomes following hepatic resection, radiofrequency ablation, and combined resection/ablation for colorectal liver metastases," Annals of Surgery, vol. 239, no. 6, pp. 818-827, 2004.

[46] T. J. White, S. H. Roy-Choudhury, D. J. Breen et al., "Percutaneous radiofrequency ablation of colorectal hepatic metastases-initial experience. An adjunct technique to systemic chemotherapy for those with inoperable colorectal hepatic metastases," Digestive Surgery, vol. 21, no. 4, pp. 314 320, 2004.

[47] G. Otto, C. Duber, M. Hoppe-Lotichius, J. Konig, M. Heise, and M. B. Pitton, "Radiofrequency ablation as first-line treatment in patients with early colorectal liver metastases amenable to surgery," Annals of Surgery, vol. 251, no. 5, pp. 796-803, 2010.

[48] S. Tsai and T. M. Pawlik, "Outcomes of ablation versus resection for colorectal liver metastases: are we comparing apples with oranges?" Annals of Surgical Oncology, vol. 16, no. 9, pp. 2422-2428, 2009.

[49] A. L. Gleisner, M. A. Choti, L. Assumpcao, H. Nathan, R. D. Schulick, and T. M. Pawlik, "Colorectal liver metastases: recurrence and survival following hepatic resection, radiofrequency ablation, and combined resection-radiofrequency ablation," Archives of Surgery, vol. 143, no. 12, pp. 1204-1212, 2008.

[50] S. Mulier, Y. Ni, J. Jamart, L. Michel, G. Marchal, and T. Ruers, "Radiofrequency ablation versus resection for resectable colorectal liver metastases: time for a randomized trial?" Annals of Surgical Oncology, vol. 15, no. 1, pp. 144-157, 2008.

[51] S. L. Wong, P. B. Mangu, M. A. Choti et al., "American Society of Clinical Oncology 2009 clinical evidence review on radiofrequency ablation of hepatic metastases from colorectal cancer," Journal of Clinical Oncology, vol. 28, no. 3, pp. 493-508, 2010.

[52] E. Berber, R. Pelley, and A. E. Siperstein, "Predictors of survival after radiofrequency thermal ablation of colorectal cancer metastases to the liver: a prospective study," Journal of Clinical Oncology, vol. 23, no. 7, pp. 1358-1364, 2005.

[53] F. F. Amersi, A. McElrath-Garza, A. Ahmad et al., "Longterm survival after radiofrequency ablation of complex unresectable liver tumors," Archives of Surgery, vol. 141, no. 6, pp. 581-588, 2006.

[54] L. Solbiati, T. Livraghi, S. N. Goldberg et al., "Percutaneous radio-frequency ablation of hepatic metastases from colorectal cancer: long-term results in 117 patients," Radiology, vol. 221, no. 1, pp. 159-166, 2001.

[55] R. M. Eisele, U. Neumann, P. Neuhaus, and G. Schumacher, "Open surgical is superior to percutaneous access for radiofrequency ablation of hepatic metastases," World Journal of Surgery, vol. 33, no. 4, pp. 804-811, 2009.

[56] M. Gagner, T. Rogula, and D. Selzer, "Laparoscopic liver resection: benefits and controversies," Surgical Clinics of North America, vol. 84, no. 2, pp. 451-462, 2004.

[57] J. Y. Cho, H. S. Han, Y. S. Yoon, and S. H. Shin, "Feasibility of laparoscopic liver resection for tumors located in the posterosuperior segments of the liver, with a special reference to overcoming current limitations on tumor location," Surgery, vol. 144, no. 1, pp. 32-38, 2008.
[58] A. A. Gumbs, B. Bar-Zakai, and B. Gayet, "Totally laparoscopic extended left hepatectomy," Journal of Gastrointestinal Surgery, vol. 12, no. 7, p. 1152, 2008.

[59] A. A. Gumbs and B. Gayet, "Multimedia article. Totally laparoscopic extended right hepatectomy," Surgical Endoscopy, vol. 22, no. 9, pp. 2076-2077, 2008.

[60] C. G. S. Huscher, M. M. Lirici, S. Chiodini, and A. Recher, "Current position of advanced laparoscopic surgery of the liver," Journal of the Royal College of Surgeons of Edinburgh, vol. 42, no. 4, pp. 219-225, 1997.

[61] G. Samama, L. Chiche, J. L. Brefort, and Y. Le Roux, "Laparoscopic anatomical hepatic resection: report of four left lobectomies for solid tumors," Surgical Endoscopy, vol. 12, no. 1, pp. 76-78, 1998.

[62] N. O'Rourke and G. Fielding, "Laparoscopic right hepatectomy: surgical technique," Journal of Gastrointestinal Surgery, vol. 8, no. 2, pp. 213-216, 2004.

[63] A. A. Gumbs and B. Gayet, "Totally laparoscopic central hepatectomy," Journal of Gastrointestinal Surgery, vol. 12, no. 7, p. $1153,2008$.

[64] J. F. Buell, D. Cherqui, D. A. Geller et al., "The international position on laparoscopic liver surgery: the Louisville statement, 2008," Annals of Surgery, vol. 250, no. 5, pp. 825-830, 2009.

[65] A. J. Koffron, G. Auffenberg, R. Kung, and M. Abecassis, "Evaluation of 300 minimally invasive liver resections at a single institution: less is more," Annals of Surgery, vol. 246, no. 3, pp. 385-392, 2007.

[66] A. Cuschieri, "Laparoscopic hand-assisted hepatic surgery," Seminars in Laparoscopic Surgery, vol. 8, no. 2, pp. 104-113, 2001.

[67] Y. Fong, W. Jarnagin, K. C. Conlon, R. DeMatteo, E. Dougherty, and L. H. Blumgart, "Hand-assisted laparoscopic liver resection: lessons from an initial experience," Archives of Surgery, vol. 135, no. 7, pp. 854-859, 2000.

[68] A. J. Koffron, R. D. Kung, G. B. Auffenberg, and M. M. Abecassis, "Laparoscopic liver surgery for everyone: the hybrid method," Surgery, vol. 142, no. 4, pp. e461-e468, 2007.

[69] A. Amodeo, A. L. Quevedo, J. V. Joseph, E. Belgrano, and H. R. H. Patel, "Robotic laparoscopic surgery: cost and training," Minerva Urologica e Nefrologica, vol. 61, no. 2, pp. 121-128, 2009.

[70] D. G. Murphy, R. Hall, R. Tong, R. Goel, and A. J. Costello, "Robotic technology in surgery: current status in 2008," ANZ Journal of Surgery, vol. 78, no. 12, pp. 1076-1081, 2008.

[71] P. C. Giulianotti, A. Coratti, F. Sbrana et al., "Robotic liver surgery: results for 70 resections," Surgery, vol. 149, no. 1, pp. 29-39, 2011.

[72] S. B. Choi, J. S. Park, J. K. Kim et al., "Early experiences of robotic-assisted laparoscopic liver resection," Yonsei Medical Journal, vol. 49, no. 4, pp. 632-638, 2008.

[73] E. Berber, H. Y. Akyildiz, F. Aucejo, G. Gunasekaran, S. Chalikonda, and J. Fung, "Robotic versus laparoscopic resection of liver tumours," HPB - Journal of the International Hepato Pancreato Biliary Association, vol. 12, no. 8, pp. 583-586, 2010.

[74] W. B. Ji, H. G. Wang, Z. M. Zhao, W. D. Duan, F. Lu, and J. H. Dong, "Robotic-assisted laparoscopic anatomic hepatectomy in China: initial experience," Annals of Surgery, vol. 253, no. 2, pp. 342-348, 2010.

[75] A. Patriti, G. Ceccarelli, A. Bartoli, A. Spaziani, L. M. Lapalorcia, and L. Casciola, "Laparoscopic and robot-assisted one-stage resection of colorectal cancer with synchronous 
liver metastases: a pilot study," Journal of Hepato-BiliaryPancreatic Surgery, vol. 16, no. 4, pp. 450-457, 2009.

[76] A. E. Chang, P. D. Schneider, P. H. Sugarbaker, C. Simpson, M. Culnane, and S. M. Steinberg, "A prospective randomized trial of regional versus systemic continuous 5-fluorodeoxyuridine chemotherapy in the treatment of colorectal liver metastases," Annals of Surgery, vol. 206, no. 6, pp. 685-693, 1987.

[77] N. Kemeny, Y. Huang, A. M. Cohen et al., "Hepatic arterial infusion of chemotherapy after resection of hepatic metastases from colorectal cancer," The New England Journal of Medicine, vol. 341, no. 27, pp. 2039-2048, 1999.

[78] T. G. Allen-Mersh, S. Earlam, C. Fordy, K. Abrams, and J. Houghton, "Quality of life and survival with continuous hepatic-artery floxuridine infusion for colorectal liver metastases," The Lancet, vol. 344, no. 8932, pp. 1255-1260, 1994.

[79] P. Rougier, A. Laplanche, M. Huguier et al., "Hepatic arterial infusion of floxuridine in patients with liver metastases from colorectal carcinoma: long-term results of a prospective randomized trial," Journal of Clinical Oncology, vol. 10, no. 7, pp. 1112-1118, 1992.

[80] D. C. Hohn, R. J. Stagg, M. A. Friedman et al., "A randomized trial of continuous intravenous versus hepatic intraarterial floxuridine in patients with colorectal cancer metastatic to the liver: the Northern California Oncology Group trial," Journal of Clinical Oncology, vol. 7, no. 11, pp. 1646-1654, 1989.

[81] C. Breedis and G. Young, "The blood supply of neoplasms in the liver," American Journal of Pathology, vol. 30, no. 5, pp. 969-977, 1954.

[82] H. S. G. Chen and J. F. Gross, "Intra-arterial infusion of anticancer drugs: theoretic aspects of drug delivery and review of responses," Cancer Treatment Reports, vol. 64, no. 1, pp. 31-40, 1980.

[83] F. Feliciotti, A. Paganini, M. Guerrieri, R. Chan, R. Campagnacci, and E. Lezoche, "Laparoscopic intra-arterial catheter implantation for regional chemotherapy of liver metastasis," Surgical Endoscopy, vol. 10, no. 4, pp. 449-452, 1996.

[84] D. R. Urbach, D. M. Herron, Y. S. Khajanchee, L. L. Swanstrom, and P. D. Hansen, "Laparoscopic hepatic artery infusion pump placement," Archives of Surgery, vol. 136, no. 6, pp. 700-704, 2001.

[85] D. R. Urbach and P. D. Hansen, "Laparoscopic placement of a continuous hepatic artery infusion pump," Seminars in Laparoscopic Surgery, vol. 7, no. 2, pp. 140-147, 2000.

[86] D. J. Martinelli, S. Wadler, C. W. Bakal et al., "Utility of embolization or chemoembolization as second-line treatment in patients with advanced or recurrent colorectal carcinoma," Cancer, vol. 74, no. 6, pp. 1706-1712, 1994.

[87] H. S. Salman, J. Cynamon, M. Jagust et al., "Randomized phase II trial of embolization therapy versus chemoembolization therapy in previously treated patients with colorectal carcinoma metastatic to the liver," Clinical Colorectal Cancer, vol. 2, no. 3, pp. 173-179, 2002.

[88] M. Albert, M. V. Kiefer, W. Sun et al., "Chemoembolization of colorectal liver metastases with cisplatin, doxorubicin, mitomycin C, ethiodol, and polyvinyl alcohol," Cancer, vol. 117, no. 2, pp. 343-352, 2010.

[89] R. A. Sharma, G. A. Van Hazel, B. Morgan et al., "Radioembolization of liver metastases from colorectal cancer using yttrium-90 microspheres with concomitant systemic oxaliplatin, fluorouracil, and leucovorin chemotherapy," Journal of Clinical Oncology, vol. 25, no. 9, pp. 1099-1106, 2007.
[90] A. Townsend, T. Price, and C. Karapetis, "Selective internal radiation therapy for liver metastases from colorectal cancer," Cochrane Database of Systematic Reviews, no. 4, artice CD007045, 2009.

[91] G. Van Hazel, A. Blackwell, J. Anderson et al., "Randomised phase 2 trial of SIR-Spheres plus fluorouracil/leucovorin chemotherapy versus fluorouracil/leucovorin chemotherapy alone in advanced colorectal cancer," Journal of Surgical Oncology, vol. 88, no. 2, pp. 78-85, 2004.

[92] K. T. Nguyen, T. C. Gamblin, and D. A. Geller, "World review of laparoscopic liver resection-2,804 patients," Annals of Surgery, vol. 250, no. 5, pp. 831-841, 2009.

[93] N. Katkhouda and E. Mavor, "Laparoscopic management of benign liver disease," Surgical Clinics of North America, vol. 80, no. 4, pp. 1203-1211, 2000.

[94] J. Fleshman, D. J. Sargent, E. Green et al., "Laparoscopic colectomy for cancer is not inferior to open surgery based on 5-year data from the COST Study Group trial," Annals of Surgery, vol. 246, no. 4, pp. 654-662, 2007.

[95] Y. Liang, G. Li, P. Chen, and J. Yu, "Laparoscopic versus open colorectal resection for cancer: a meta-analysis of results of randomized controlled trials on recurrence," European Journal of Surgical Oncology, vol. 34, no. 11, pp. 1217-1224, 2008.

[96] L. Aldrighetti, C. Pulitano, M. Catena et al., "A prospective evaluation of laparoscopic versus open left lateral hepatic sectionectomy," Journal of Gastrointestinal Surgery, vol. 12, no. 3, pp. 457-462, 2008.

[97] M. Abu Hilal, M. J. W. McPhail, B. Zeidan et al., "Laparoscopic versus open left lateral hepatic sectionectomy: a comparative study," European Journal of Surgical Oncology, vol. 34, no. 12, pp. 1285-1288, 2008.

[98] I. Dagher, G. Di Giuro, J. Dubrez, P. Lainas, C. Smadja, and D. Franco, "Laparoscopic versus open right hepatectomy: a comparative study," American Journal of Surgery, vol. 198, no. 2, pp. 173-177, 2009.

[99] K. Ito, H. Ito, C. Are et al., "Laparoscopic versus open liver resection: a matched-pair case control study," Journal of Gastrointestinal Surgery, vol. 13, no. 12, pp. 2276-2283, 2009.

[100] M. Tsinberg, G. Tellioglu, C. H. Simpfendorfer et al., "Comparison of laparoscopic versus open liver tumor resection: a case-controlled study," Surgical Endoscopy, vol. 23, no. 4, pp. 847-853, 2009.

[101] B. Topal, S. Fieuws, R. Aerts, H. Vandeweyer, and F. Penninckx, "Laparoscopic versus open liver resection of hepatic neoplasms: comparative analysis of short-term results," Surgical Endoscopy, vol. 22, no. 10, pp. 2208-2213, 2008.

[102] F. M. Polignano, A. J. Quyn, R. S. M. de Figueiredo, N. A. Henderson, C. Kulli, and I. S. Tait, "Laparoscopic versus open liver segmentectomy: prospective, case-matched, intentionto-treat analysis of clinical outcomes and cost effectiveness," Surgical Endoscopy, vol. 22, no. 12, pp. 2564-2570, 2008.

[103] K. T. Nguyen, J. W. Marsh, A. Tsung, J. J. Steel, T. C. Gamblin, and D. A. Geller, "Comparative benefits of laparoscopic vs open hepatic resection: a critical appraisal," Archives of Surgery, vol. 146, no. 3, pp. 348-356, 2010.

[104] K. T. Nguyen, A. Laurent, I. Dagher et al., "Minimally invasive liver resection for metastatic colorectal cancer: a multi-institutional, international report of safety, feasibility, and early outcomes," Annals of Surgery, vol. 250, no. 5, pp. 842-848, 2009.

[105] D. Castaing, E. Vibert, L. Ricca, D. Azoulay, R. Adam, and B. Gayet, "Oncologic results of laparoscopic versus open 
hepatectomy for colorectal liver metastases in two specialized centers," Annals of Surgery, vol. 250, no. 5, pp. 849-855, 2009.

[106] I. Dagher, N. O’Rourke, D. A. Geller et al., "Laparoscopic major hepatectomy: an evolution in standard of care," Annals of Surgery, vol. 250, no. 5, pp. 856-860, 2009.

[107] R. J. de Haas, D. A. Wicherts, E. Flores, D. Azoulay, D. Castaing, and R. Adam, "R1 resection by necessity for colorectal liver metastases: is it still a contraindication to surgery?" Annals of Surgery, vol. 248, no. 4, pp. 626-637, 2008.

[108] M. A. Choti, J. V. Sitzmann, M. F. Tiburi et al., "Trends in long-term survival following liver resection for hepatic colorectal metastases," Annals of Surgery, vol. 235, no. 6, pp. 759-766, 2002.

[109] T. M. Pawlik, C. R. Scoggins, D. Zorzi et al., "Effect of surgical margin status on survival and site of recurrence after hepatic resection for colorectal metastases," Annals of Surgery, vol. 241, no. 5, pp. 714-722, 2005.

[110] F. K. S. Welsh, P. P. Tekkis, T. G. John, and M. Rees, "Open liver resection for colorectal metastases: better shortand long-term outcomes in patients potentially suitable for laparoscopic liver resection," HPB-Journal of the International Hepato Pancreato Biliary Association, vol. 12, no. 3, pp. 188-194, 2010.

[111] J. F. Buell, M. T. Thomas, S. Rudich et al., "Experience with more than 500 minimally invasive hepatic procedures," Annals of Surgery, vol. 248, no. 3, pp. 475-485, 2008.

[112] T. Vanounou, J. L. Steel, K. T. Nguyen et al., "Comparing the clinical and economic impact of laparoscopic versus open liver resection," Annals of Surgical Oncology, vol. 17, no. 4, pp. 998-1009, 2010.

[113] R. M. van Dam, P. O. Hendry, M. M. E. Coolsen et al., "Initial experience with a multimodal enhanced recovery programme in patients undergoing liver resection," British Journal of Surgery, vol. 95, no. 8, pp. 969-975, 2008.

[114] J. Khan, T. M. Pawlik, and S. C. Cunningham, "No small issue: hepatectomies-minimally invasive but more-thanminimally biased toward minor resections?" Journal of the American College of Surgerons, vol. 212, no. 1, pp. 134-135, 2010.

[115] S. Gagandeep and R. Selby, "Laparoscopic liver resections: extent of resection defines length of stay," Journal Gastrointestinal Surgery, vol. 10, no. 8, pp. 1188-1189, 2006.

[116] T. van Gulik, "Open versus laparoscopic resection for liver tumours," HPB-Journal of the International Hepato Pancreato Biliary Association, vol. 11, no. 6, pp. 465-468, 2009.

[117] C. Simillis, V. A. Constantinides, P. P. Tekkis et al., "Laparoscopic versus open hepatic resections for benign and malignant neoplasms-a meta-analysis," Surgery, vol. 141, no. 2, pp. 203-211, 2007.

[118] J. S. Barkun, J. K. Aronson, L. S. Feldman, G. J. Maddern, and S. M. Strasberg, "Evaluation and stages of surgical innovations," The Lancet, vol. 374, no. 9695, pp. 1089-1096, 2009.

[119] K. S. Lehmann, J. P. Ritz, A. Wibmer et al., "The German registry for natural orifice translumenal endoscopic surgery: report of the first 551 patients," Annals of Surgery, vol. 252, no. 2, pp. 263-270, 2010.

[120] S. J. Phee, K. Y. Ho, D. Lomanto et al., "Natural orifice transgastric endoscopic wedge hepatic resection in an experimental model using an intuitively controlled master and slave transluminal endoscopic robot (MASTER)," Surgical Endoscopy, vol. 24, no. 9, pp. 2293-2298, 2010.
[121] J. F. Noguera, C. Dolz, A. Cuadrado, J. M. Olea, and A. Vilella, "Transvaginal liver resection (NOTES) combined with minilaparoscopy," Revista Espanola de Enfermedades Digestivas, vol. 100, no. 7, pp. 411-415, 2008.

[122] AHPBA, "Advanced GI Surgery Curriculum for HepatoPancreato-Biliary Surgery Fellowship; Appendix, Version April 21, 2010," http://www.fellowshipcaselog.org/fellows/ FC_Guidelines_for_Logging_HPB_Cases.pdf.

[123] E. Wang, A. W. C. Kow, C. Y. Chan, K. H. Liau, and C. K. Ho, "Starting a laparoscopic hepatectomy programme," Singapore Medical Journal, vol. 50, no. 4, pp. 354-359, 2009.

[124] S. Chang, A. Laurent, C. Tayar, M. Karoui, and D. Cherqui, "Laparoscopy as a routine approach for left lateral sectionectomy," British Journal of Surgery, vol. 94, no. 1, pp. 58-63, 2007.

[125] I. Dagher, J. M. Proske, A. Carloni, H. Richa, H. Tranchart, and D. Franco, "Laparoscopic liver resection: results for 70 patients," Surgical Endoscopy, vol. 21, no. 4, pp. 619-624, 2007.

[126] L. Vigano, A. Laurent, C. Tayar, M. Tomatis, A. Ponti, and D. Cherqui, "The learning curve in laparoscopic liver resection: improved feasibility and reproducibility," Annals of Surgery, vol. 250, no. 5, pp. 772-782, 2009.

[127] P. P. Tekkis, A. J. Senagore, C. P. Delaney, and V. W. Fazio, "Evaluation of the learning curve in laparoscopic colorectal surgery: comparison of right-sided and left-sided resections," Annals of Surgery, vol. 242, no. 1, pp. 83-91, 2005.

[128] E. Pihl, E. S. R. Hughes, and F. T. McDermott, "Lung recurrence after curative surgery for colorectal cancer," Diseases of the Colon and Rectum, vol. 30, no. 6, pp. 417-419, 1987.

[129] J. R. Headrick, D. L. Miller, D. M. Nagorney et al., "Surgical treatment of hepatic and pulmonary metastases from colon cancer," Annals of Thoracic Surgery, vol. 71, no. 3, pp. 975980, 2001.

[130] K. Kobayashi, M. Kawamura, and T. Ishihara, "Surgical treatment for both pulmonary and hepatic metastases from colorectal cancer," Journal of Thoracic and Cardiovascular Surgery, vol. 118, no. 6, pp. 1090-1096, 1999.

[131] S. Murata, Y. Moriya, T. Akasu, S. Fujita, and K. Sugihara, "Resection of both hepatic and pulmonary metastases in patients with colorectal carcinoma," Cancer, vol. 83, no. 6, pp. 1086-1093, 1998.

[132] J. F. Regnard, D. Grunenwald, L. Spaggiari et al., "Surgical treatment of hepatic and pulmonary metastases from colorectal cancers," Annals of Thoracic Surgery, vol. 66, no. 1, pp. 214-219, 1998.

[133] R. Marudanayagam, K. Ramkumar, V. Shanmugam et al., "Long-term outcome after sequential resections of liver and lung metastases from colorectal carcinoma," HPB-Journal of the International Hepato Pancreato Biliary Association, vol. 11, no. 8, pp. 671-676, 2009.

[134] S. Limmer, E. Oevermann, C. Killaitis, P. Kujath, M. Hoffmann, and H. P. Bruch, "Sequential surgical resection of hepatic and pulmonary metastases from colorectal cancer," Langenbeck's Archives of Surgery, vol. 395, no. 8, pp. 11291138, 2010.

[135] J. Pfannschmidt, H. Hoffmann, and H. Dienemann, "Reported outcome factors for pulmonary resection in metastatic colorectal cancer," Journal of Thoracic Oncology, vol. 5, supplement 2, no. 6, pp. S172-S178, 2010.

[136] D. R. Carpizo and M. D'Angelica, "Liver resection for metastatic colorectal cancer in the presence of extrahepatic disease," Annals of Surgical Oncology, vol. 16, no. 9, pp. 24112421, 2009. 
[137] M. Riquet, C. Foucault, A. Cazes et al., "Pulmonary resection for metastases of colorectal adenocarcinoma," Annals of Thoracic Surgery, vol. 89, no. 2, pp. 375-380, 2010.

[138] K. Yamakado, Y. Inoue, M. Takao et al., "Long-term results of radiofrequency ablation in colorectal lung metastases: single center experience," Oncology Reports, vol. 22, no. 4, pp. 885891, 2009.

[139] D. G. Jayne, S. Fook, C. Loi, and F. Seow-Choen, "Peritoneal carcinomatosis from colorectal cancer," British Journal of Surgery, vol. 89, no. 12, pp. 1545-1550, 2002.

[140] M. J. Koppe, O. C. Boerman, W. J. G. Oyen, and R. P. Bleichrodt, "Peritoneal carcinomatosis of colorectal origin: incidence and current treatment strategies," Annals of Surgery, vol. 243, no. 2, pp. 212-222, 2006.

[141] L. Maggiori and D. Elias, "Curative treatment of colorectal peritoneal carcinomatosis: current status and future trends," European Journal of Surgical Oncology, vol. 36, no. 7, pp. 599603, 2010.

[142] V. J. Verwaal, S. van Ruth, E. de Bree et al., "Randomized trial of cytoreduction and hyperthermic intraperitoneal chemotherapy versus systemic chemotherapy and palliative surgery in patients with peritoneal carcinomatosis of colorectal cancer," Journal of Clinical Oncology, vol. 21, no. 20, pp. 3737-3743, 2003.

[143] D. Elias, J. H. Lefevre, J. Chevalier et al., "Complete cytoreductive surgery plus intraperitoneal chemohyperthermia with oxaliplatin for peritoneal carcinomatosis of colorectal origin," Journal of Clinical Oncology, vol. 27, no. 5, pp. 681$685,2009$.

[144] T. C. Chua, T. D. Yan, J. Zhao, and D. L. Morris, "Peritoneal carcinomatosis and liver metastases from colorectal cancer treated with cytoreductive surgery perioperative intraperitoneal chemotherapy and liver resection," European Journal of Surgical Oncology, vol. 35, no. 12, pp. 1299-1305, 2009.

[145] D. Elias, P. Dube, S. Bonvalot et al., "Treatment of liver metastases with moderate peritoneal carcinomatosis by hepatectomy and cytoreductive surgery followed by immediate post-operative intraperitoneal chemotherapy: feasibility and preliminary results," Hepato-Gastroenterology, vol. 46, no. 25, pp. 360-363, 1999.

[146] C. P. Carmignani, G. Ortega-Perez, and P. H. Sugarbaker, "The management of synchronous peritoneal carcinomatosis and hematogenous metastasis from colorectal cancer," European Journal of Surgical Oncology, vol. 30, no. 4, pp. 391-398, 2004.

[147] D. Elias, E. Benizri, M. Pocard, M. Ducreux, V. Boige, and P. Lasser, "Treatment of synchronous peritoneal carcinomatosis and liver metastases from colorectal cancer," European Journal of Surgical Oncology, vol. 32, no. 6, pp. 632-636, 2006.

[148] P. Jacquet and P. H. Sugarbaker, "Clinical research methodologies in diagnosis and staging of patients with peritoneal carcinomatosis," Cancer Treatment and Research, vol. 82, pp. 359-374, 1996.

[149] P. A. van Dam, P. J. H. van Dam, L. Verkinderen, P. Vermeulen, F. Deckers, and L. Y. Dirix, "Robotic-assisted laparoscopic cytoreductive surgery for lobular carcinoma of the breast metastatic to the ovaries," Journal of Minimally Invasive Gynecology, vol. 14, no. 6, pp. 746-749, 2007.

[150] Y. L. He, L. Y. Zhang, and D. X. Peng, "[Laparoscopic cytoreductive surgery for ovarian carcinoma: report of 4 cases]," Di Yi Jun Yi Da Xue Xue Bao, vol. 24, no. 4, pp. 479480, 2004 .
[151] A. Knutsen, T. D. Sielaff, E. Greeno, and T. M. Tuttle, "Staged laparoscopic infusion of hyperthermic intraperitoneal chemotherapy after cytoreductive surgery," Journal of Gastrointestinal Surgery, vol. 10, no. 7, pp. 1038-1043, 2006.

[152] J. Esquivel, T. C. Chua, and A. Averbach, "Laparoscopic cytoreductive surgery and HIPEC in patients with limited peritoneal surface malignancies," Annals of Surgery, vol. 253, no. 4, pp. 764-768, 2011. 


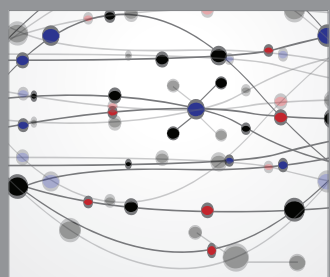

The Scientific World Journal
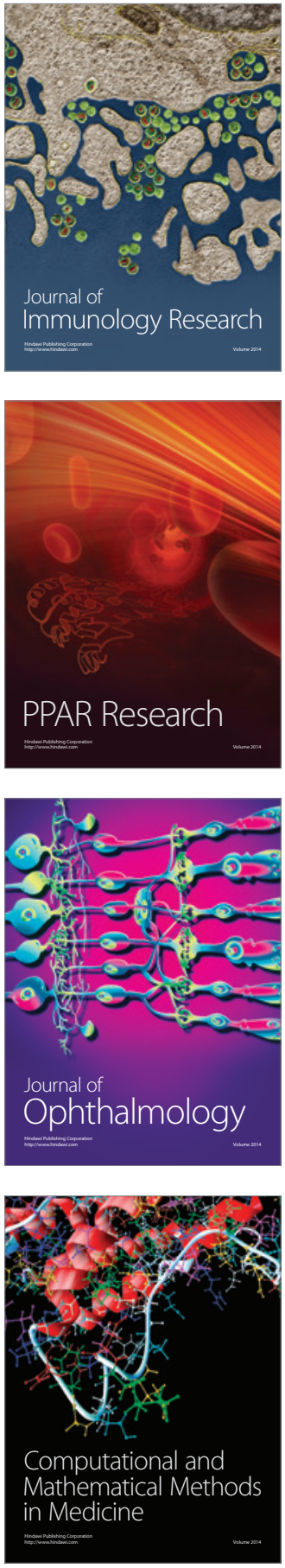

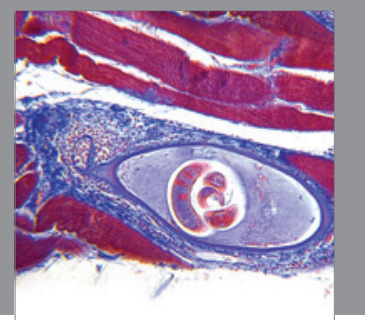

Gastroenterology

Research and Practice
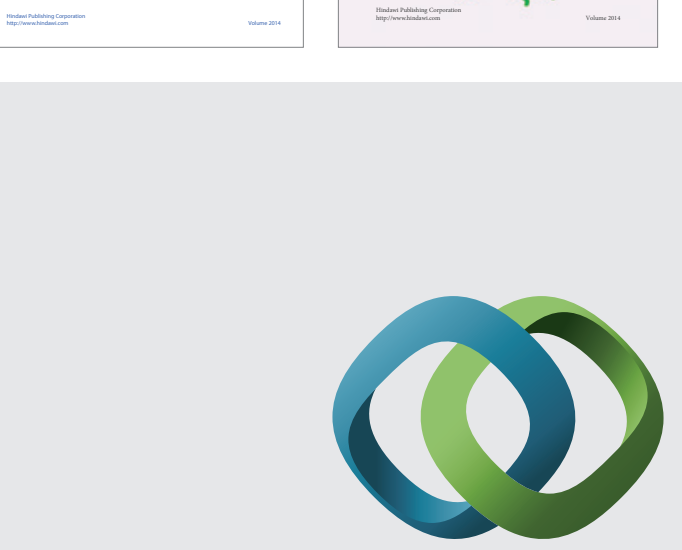

\section{Hindawi}

Submit your manuscripts at

http://www.hindawi.com
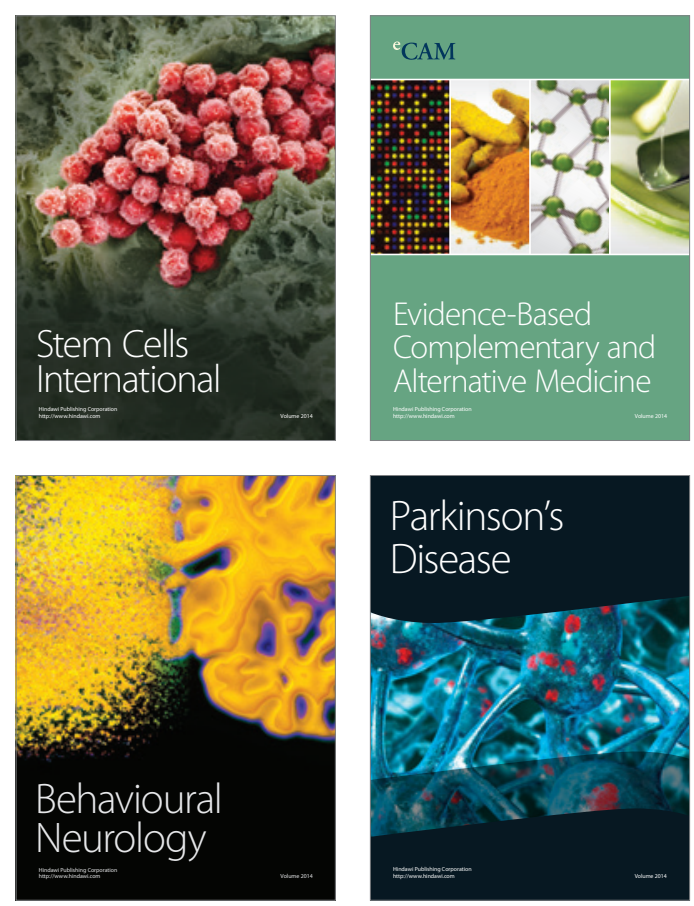

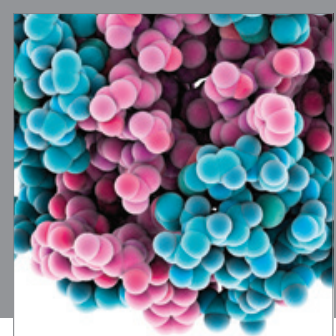

Journal of
Diabetes Research

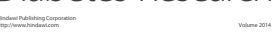

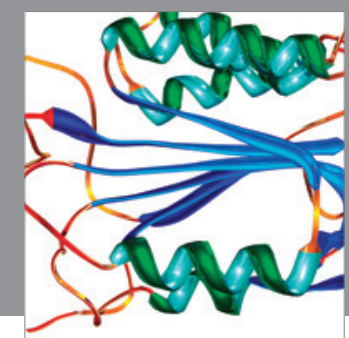

Disease Markers
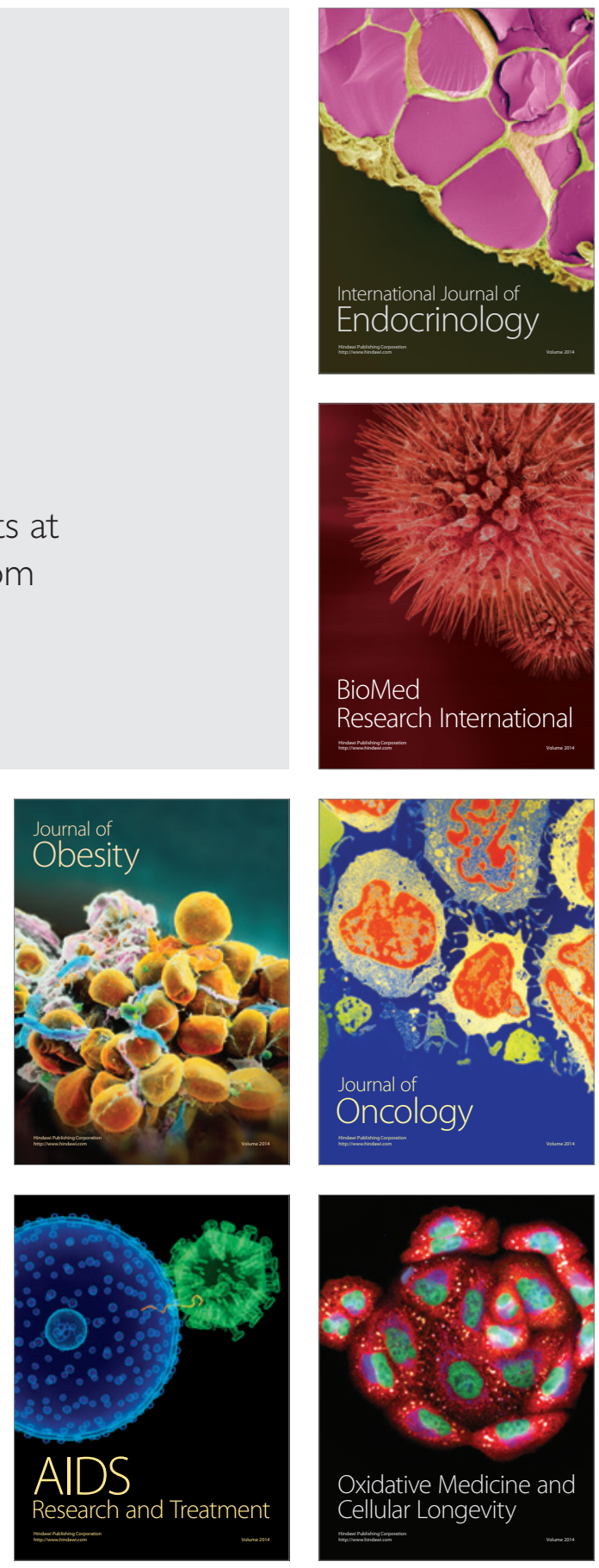